\title{
Influence of the calculation grid density to the resulting photometric parameters of public lighting
}

\begin{abstract}
.
Calculation and measurement of performance parameters of public lighting are performed in a grid of points defined by the CIE publication 140 [1] and European standard EN 13201-3.[2] Calculation grid defined in these documents was created at a time of less powerful computers and less precise measuring technology. Distance between two adjacent calculating points may be even $3 \mathrm{~m}$, depending on the geometry of the road. This arrangement is too sparse in view of the fact that presently used computers can cope with much more denser grids in a shorter operation time and the measurement can be performed by luminance analyzers with more accuracy as well. Between the results of the calculation with different grid densities of calculation points there can be significant differences. This fact can be influenced by new optical systems and some LED luminaires which, as it was found out by measurements, may contain various local extremes in the LIDC. When calculating the performance parameters of public lighting with given grid density these extremes may fall between calculation points and thus they are not included in the calculation. The solution is to propose a new density of calculation points which would be designed with respect to current possibilities of computer and measuring technology.

The paper deals with the influence of grid density to the resulting photometric parameters of public lighting. In computing software, calculation grid of points according to EN 13201-3 and calculation grid with half and 2 to 10-times densification of calculation points will be used in order to capture the impact of given local extremes to the resulting parameters using luminaires with different optical systems. The results of these calculations will be used as the basis to determine an appropriate density of calculation and measurement grid. The results will be used in the preparation of future revisions of normative documents, which provide a method for determining points of calculation and measurement grid.
\end{abstract}

Keywords: Calculation, measurement, public lighting, density.

\section{Introduction}

Calculation field has a exactly defined position in the transverse and longitudinal direction (Fig. 1). In the longitudinal direction on a straight road, the field of calculation should lie between two consecutive luminaires in the same row In the transverse direction, it should cover the whole carriageway width for roads without a central reservation, and the width of one carriageway for roads with a central reservation. Observer position is defined in the axis of each lane in height $1.5 \mathrm{~m}$ (it corresponding to the height of the observer eye in the car) and at a distance of $60 \mathrm{~m}$ before the first luminaire in the field of calculation which results from the application area of R-tables which are measured for the angle of observation $\alpha=1^{\circ}$. R-Table may be used in the range of angle of observation from $\alpha=$ $0.5^{\circ}$ to $\alpha=1.5^{\circ}$. At a height of observer eye 1.5 meters, it represents observer distances from $57 \mathrm{~m}$ to $172 \mathrm{~m}$. In the CIE 30.2 [3] was defined position of the observer in 1/4 of lane closer to the right side. Observer position by CIE 140 better reflects the real position.

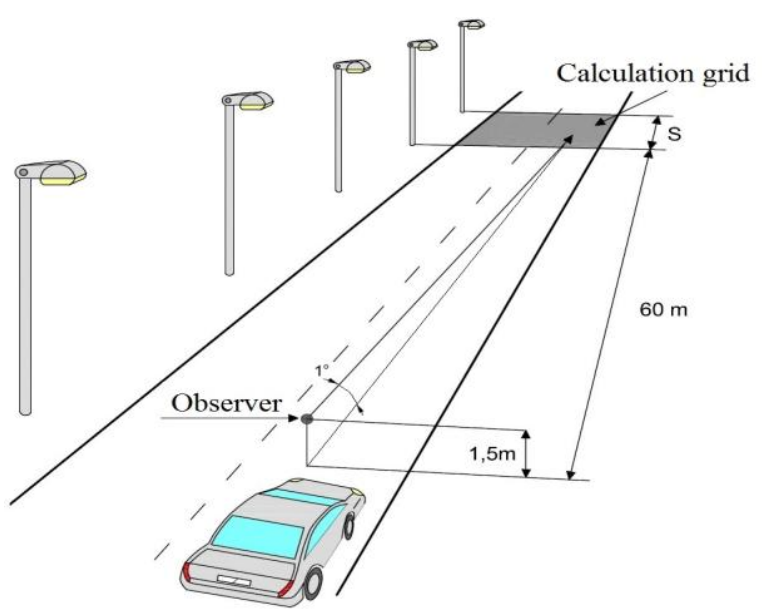

Fig.1. Location of calculation field
The calculation points should be evenly spaced in the field of calculation and located as indicated in Fig. 2. The number of calculation points in the longitudinal direction is defined by (1) and in the transverse direction by (2).

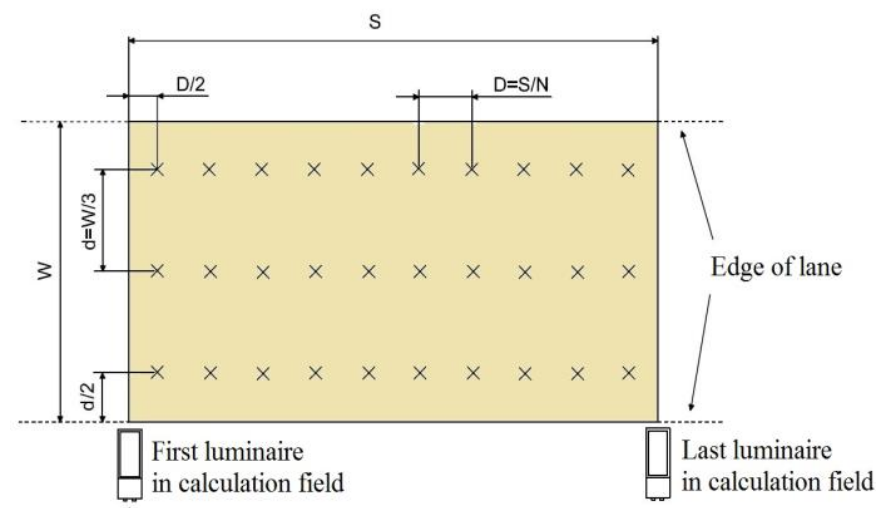

Fig.2. Calculation points

$$
D=\frac{s}{N}(1) \quad d=\frac{W}{3}(2)
$$

D is the spacing between points in the longitudinal direction, $\mathbf{S}$ is the spacing between luminaires in the same row, $\mathbf{N}$ is the number of calculation points in the longitudinal direction with the following values:

for $\mathrm{S} \leq 30 \mathrm{~m}, \mathrm{~N}=10$;

for $S>30 \mathrm{~m}$, the smallest integer giving $\mathrm{D} \leq 3 \mathrm{~m}$.

The first transverse row of calculation points is spaced at a distance $\mathrm{D} / 2$ beyond the first luminaire,

$\mathbf{d}$ is the spacing between points in the transverse direction, $\mathbf{W}$ is the width of the lane, in metres

Currently, the number of calculation points in the field of calculation for lane is in the range $3 \times 10$ to $3 \times 14$ points, depending on the geometry of communication and luminaires arrangement. 
Given the progress in computer technology and automated measurement of photometric parameters of luminaires is currently used thicker angular interval. In CIE 140 are required measuring angular intervals in photometric azimuth (C) shall at most be $5^{\circ}$ and in vertical photometric angle $(\gamma)$ shall at most be $2.5^{\circ}$. Currently used goniophotometers depending on the type are capable of measuring with the resolitions about $0.5^{\circ}-1^{\circ}$. Useing the thicker intervals have a major impact in modern LED luminaires which, depending on the optical system may include local extremes (Fig. 3). Using a less dense interval would not be theese extremes captured. When the local extremes are not included in the calculation we get misstatement results(Lav, UO, UI, ...). These extremes in angular intervals can cause glare.

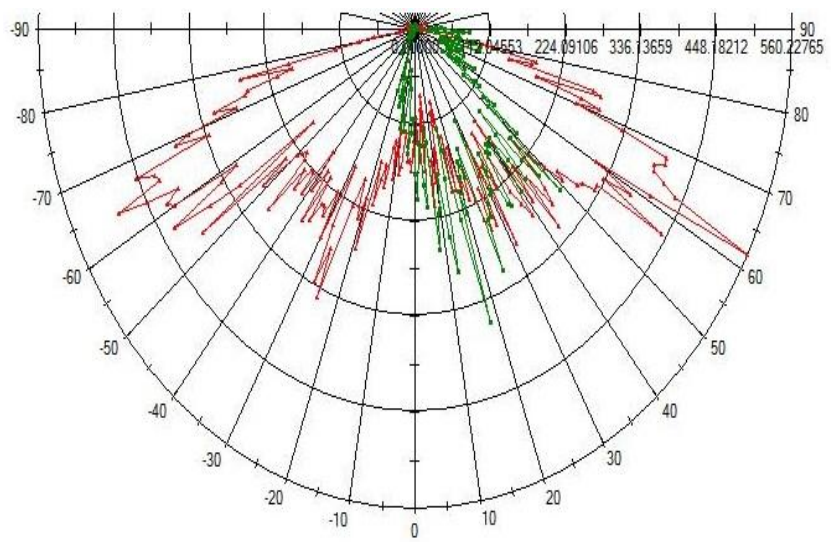

Fig.3. LIDC which contain a local extremes

\section{Simulation}

The simulation will be considered with the following assumptions:

- not considering the lighting classes,

- the road surface is unified for all types of communication,

- Maintenance factor is equal to 1.

Lighting classes can be neglected due to the fact that in the simulations will examine the impact of various LIDC to the resulting photometric parameters. In the calculation will change the density of calculation points and types of LIDC, then investigated the influence of final density to the selected photometric parameters which are the average luminance (Lav), the overall uniformity (U0), the longitudinal uniformity (UI). For all calculations will use road surfaces R3 presenting asphalt surface with aggregate composed of a minimum of $60 \%$ gravel of size greater than $10 \mathrm{~mm}$. Given that it will consider percentage change of individual parameters can be neglected the impact of the maintenance factor. For the simulation was selected geometry shown in table 1. LIDC were selected so that represent the widest possible range used LIDC in road lighting (Fig.4).

Table 1. Geometry using in simulation
\begin{tabular}{|l|c|c|}
\hline \multirow{2}{*}{ Geometry } & \multicolumn{2}{|c|}{ Calculation } \\
\cline { 2 - 3 } & $1-4,6-16$ & 5 \\
\hline Road width & $6 \mathrm{~m}$ & $4 \mathrm{~m}$ \\
\hline Number of lanes & 2 & 1 \\
\hline Arrangement & \multicolumn{2}{|c|}{ single-sided left } \\
\hline Mounting height & \multicolumn{2}{|c|}{$8 \mathrm{~m}$} \\
\hline Pole spacing & \multicolumn{2}{|c|}{$30 \mathrm{~m}$} \\
\hline Tilt angle & \multicolumn{2}{|c|}{$0^{\circ}$} \\
\hline Overhang & \multicolumn{2}{|c|}{$0 \mathrm{~m}$} \\
\hline
\end{tabular}

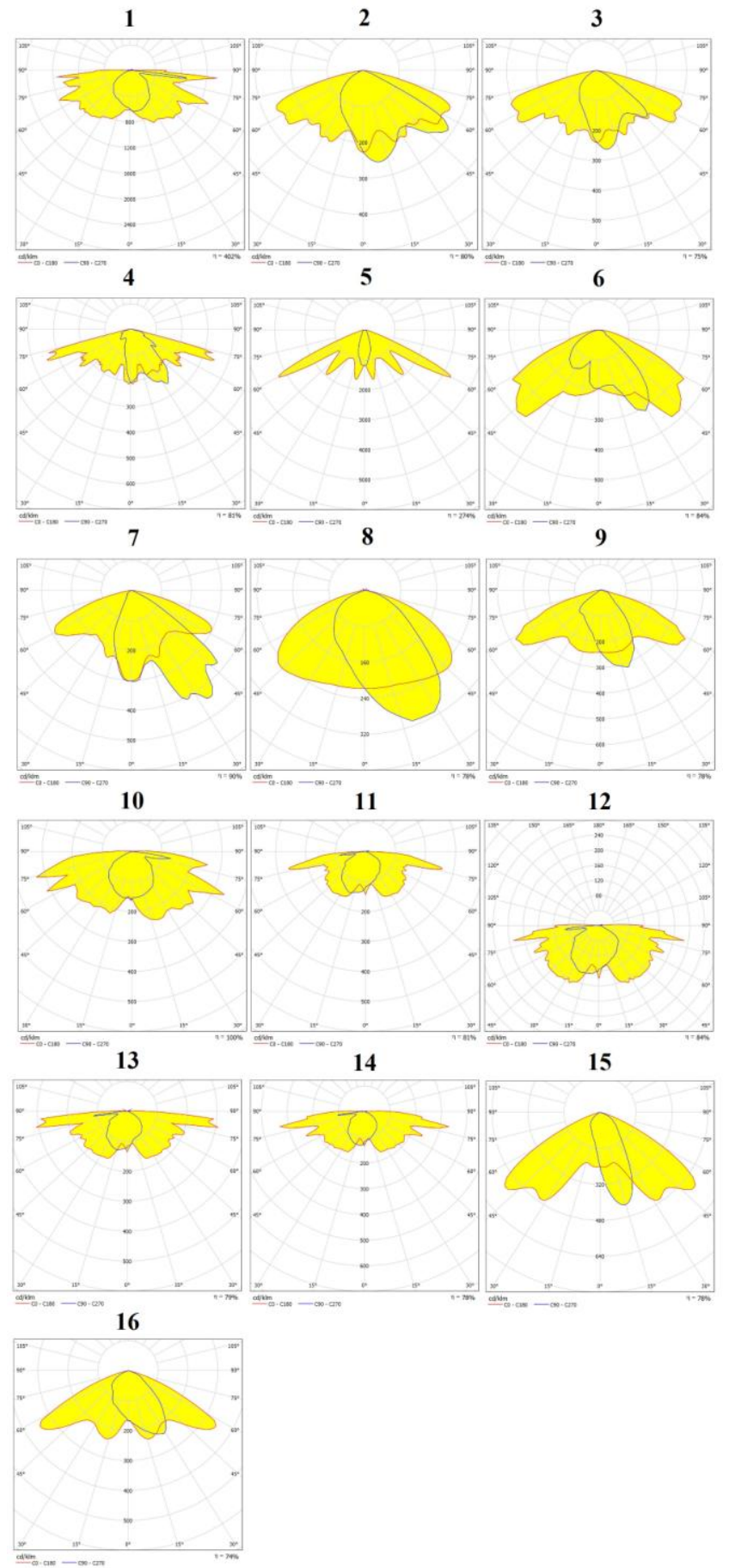

Fig.4. LIDC of luminaires using in simulation

In the calculations are used more settings of calculation grid. For each calculations are used calculation grid according table 2 . The second row of the table represents the basic layout of calculation points according to CIE 140 . Other lines represent $0.5 ; 2 ; 4 ; 8$ and 10 -times densification points from the basic layout.

Table 2. Density of calculation points

\begin{tabular}{|c|c|c|}
\hline \multirow{2}{*}{ Density } & $\begin{array}{c}\text { The number of calculation } \\
\text { points in the transverse } \\
\text { direction }\end{array}$ & $\begin{array}{c}\text { The number of calculation points in } \\
\text { the longitudinal direction }\end{array}$ \\
\cline { 3 - 3 } & 3 & $\mathrm{~S} \leq 30 \mathrm{~m}$ \\
\hline 2 & 6 & 5 \\
\hline 3 & 12 & 10 \\
\hline 4 & 24 & 20 \\
\hline 5 & 48 & 40 \\
\hline 6 & 60 & 80 \\
\hline
\end{tabular}




\section{Results of simulation}

Calculated values of selected parameters of road lighting are shown in tables 1-3. In these tables are show values at various settings of density of calculation grid for each calcuation. The geometry of the road and luminaire arrangement is shown in Table 1. Change of the resulting value of individual selected parameter is different and depends on the luminaire type and its LIDC. (Fig.4.) For luminaires containing a higher number of local extremes was the change of the individual parameters especially Uo and UI greater.

Table 3. Calculated values of Lav

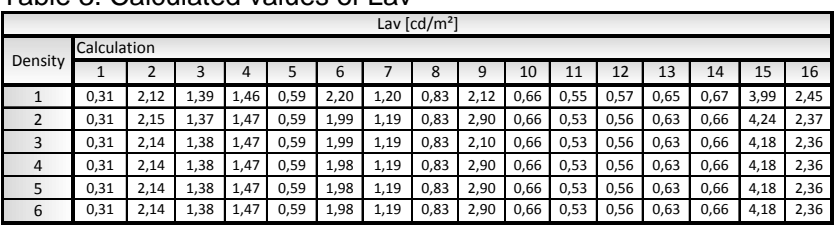

Table 4. Calculated values of U0

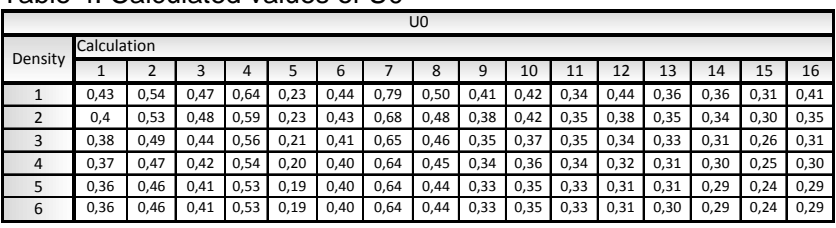

Table 5. Calculated values of UI

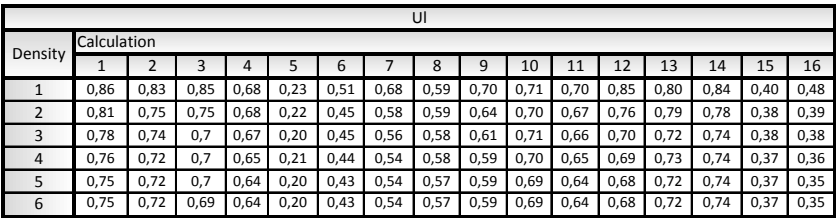

In tables 6-8 and figures 5-7 are shown percentage changes of selected parameters. The results show that the density change in most cases does not have a major impact to the results of Lav. However have a not inconsiderable impact to UO and UI. In 8 times densified of calculation grid will change resulting values of U0 approximately from 5 to $20 \%$ and UI approximately from 1 to $10 \%$. It was found that a 10-times thickening of density of calculation grid has no effect on the resulting parameters and therefore is not necessary.

Table 6. Impact of changes the density of calculation grid to Lav

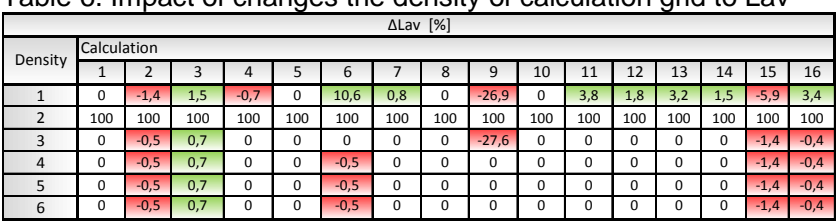

Table 7. Impact of changes the density of calculation grid to $\cup 0$

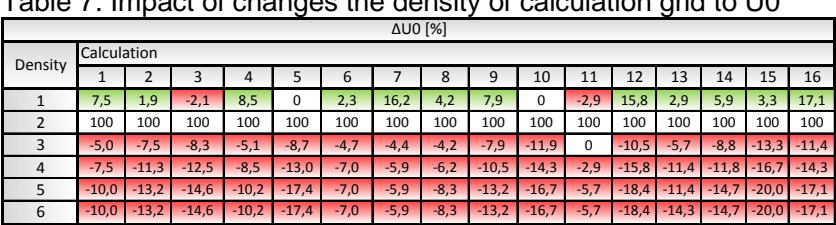

Table 8. Impact of changes the density of calculation grid to UI

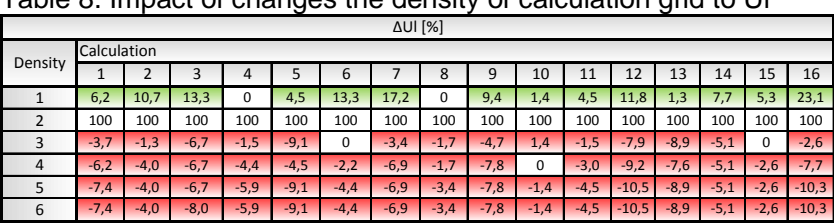

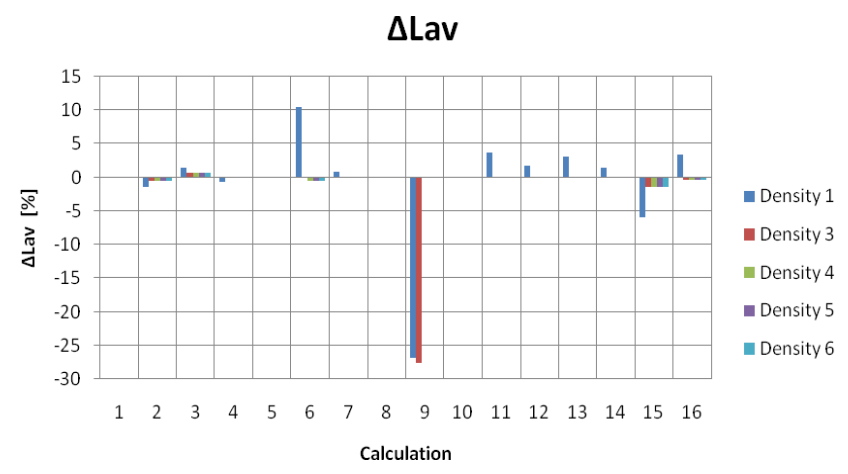

Fig.5. Impact of changes the density of calculation grid to Lav

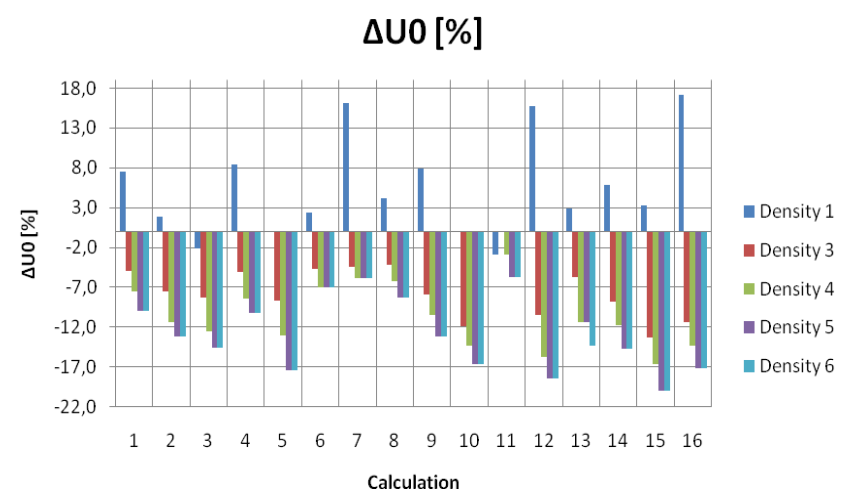

Fig.6. Impact of changes the density of calculation grid to UO

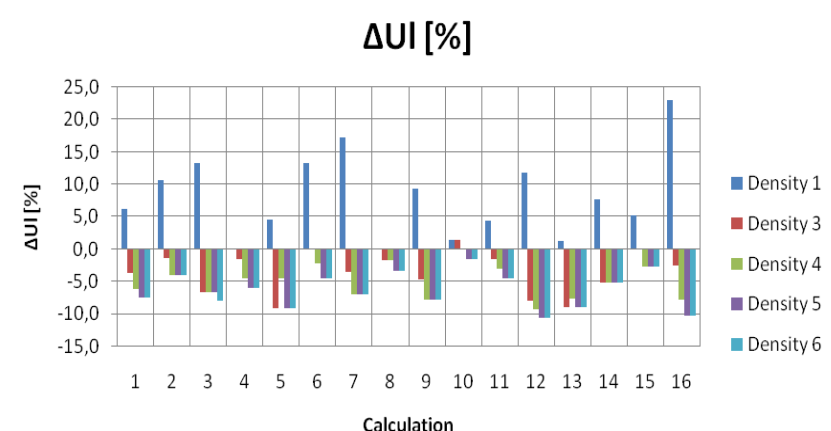

Fig.7. Impact of changes the density of calculation grid to $\mathrm{UI}$

\section{Conclusion}

It was found that the densification of calculation grid has impact on the resulting photometric parameters of public lighting. Calculation grid defined in standards was created at a time of less powerful computers and less precise measuring technology. Currently, the development of these devices has progressed and it is therefore necessary to consider the possibility of creating a new calculation grid with a greater density of calculation points. Creation of new calculation grid is necessary mainly because the new type of luminaires (LED, luminaires with faceted reflectors) contain local extremes in LIDC. If these local extremes are not included in the calculation we get inaccurate results (especially UO and UI). Differences can by up to $20 \%$ as was shown in the simulation. In creation of new calculation grid can be considered 8 times densifying of calculation points, greater densification of points has not impact on the results. It is also necessary to think about densifying of measurement points because currently we can perform measurements by using luminance measuring camera. 


\section{Acknowledgment}

This paper is supported by the agency VEGA MŠVVaŠ SR under Grant No.

VEGA 1/0988/12 „Energy efficiency of lighting systems in buildings".

\section{REFERENCES}

[1] CIE 140 (2000) Roadlighting Calculations, ISBN 3901906037

[2] EN 13 201-3:2003, Road lighting part 3.

Calculation of performances

[3] CIE 30.2 (1982) Calculation and Measurement of Luminance and Illuminance in Road Lighting, ISBN 92-9034-030-4

Authors: Ing. Lukáš Lipnický, Slovenská technická univerzita $v$ Bratislave Fakulta elektrotechniky a informatiky, Ilkovičova 3, Bratislava, Slovak Republic,

e-mail: lukas.lipnicky@stuba.sk

doc. Ing. Dionýz Gašparovský, PhD., Slovenská technická univerzita $v$ Bratislave Fakulta elektrotechniky a informatiky,

Ilkovičova 3, Bratislava, Slovak Republic,

e-mail: dionyz.gasparovsky@stuba.sk 